\title{
Antibiotic Resistance in Escherichia coli and Staphylococcus aureus from Retail Chicken Meat in Surabaya, Indonesia
}

\author{
Annisa Aulia Maghfirani Sudarmadi ${ }^{1}$, Subur Prajitno², Agung Dwi Wahyu Widodo $^{3^{*}}$ \\ ${ }^{1}$ Faculty of Medicine, Universitas Airlangga, Surabaya, Indonesia \\ ${ }^{2}$ Department of Public Health and Preventive Medicine, Faculty of Medicine, Universitas Airlangga, Surabaya, Indonesia \\ ${ }^{3}$ Department of Microbiology, Faculty of Medicine, Universitas Airlangga, Surabaya, Indonesia
}

\section{A R T I C L E I N F O}

\section{Article history:}

Received 22 September 2020

Received in revised form 27

October 2020

Accepted 29 October 2020

Available online 31 October 2020

Keywords:

Chicken meat

Antibiotic resistance,

Escherichia coli,

Staphylococcus aureus,

Cephalosporins.

*) Corresponding author: agungmd_imun@yahoo.co.id

\begin{abstract}
A B S T RA C T
Introduction: Antimicrobial resistance is becoming a problem in public health. Zoonotic foodborne bacteria is infectious agent that can be transferred from animal to human through the foodproducing animal we consume. Nowadays, antibiotic used for human and animal is not only to cure infection but also to aim animal's growth promotion. It is known as non therapeutic antimicrobial agent (NTA) leading to antibiotic resistance. The third generation cephalosporins, cefotaxime, and also cefoxitin are included as important antibiotic for human. This study aims to identify the presence of cefotaxime-resistant Escherichia coli and cefoxitin-resistant Staphylococcus aureus isolated from chicken meat of both traditional and modern market in Surabaya.

Methods: This is descriptive post test only experimental research. We used 8 samples of chicken meat from 4 different market using purposive sampling technique. We cultured Escherichia coli and Staphylococcus aureus from the chicken meat. Sensitivity test was done using Kirby-bauer disk-diffusion method.

Results: All chicken meat sample bought from traditional market in Surabaya are contaminated by cefotaxime-sensitive Escherichia coli $(\mathrm{n}=4 / 4)$ while chicken meat sample bought from modern market are not contaminated by Escherichia coli $(\mathrm{n}=0 / 4)$. All chicken meat sample bought from traditional $(\mathrm{n}=4 / 4)$ are also contaminated by cefoxitin-sensitive Staphylococcus aureus. Half of chicken meat sample bought from modern market $(n=2 / 4)$ are contaminated by cefoxitin-sensitive Staphylococcus aureus, while the other half $(\mathrm{n}=2 / 4)$ are contaminated by cefoxitin-resistant Staphylococcus aureus.

Conclusion: Antibiotic resistance is found and all chicken meat samples have been highly contaminated with bacteria therefore food-processing should be done correctly.
\end{abstract}

\begin{abstract}
Introduction
Antimicrobial resistance acquired from food-producing animal is now becoming one of world's health problem.1 Furthermore, food-borne pathogenic bacteria is known to be the cause of $75 \%$ infectious diseases in human. It is responsible for deaths and high medical cost in developing countries. $^{2}$ The increased occurrence of antimicrobial resistance is highly linked with the usage of non-therapeutic antimicrobial agent. Nowadays, antibiotic is not only used to treat infectious diseases but also to promote growth, especially in broiler chicken as a food-producing animal. ${ }^{3}$ If this to be happen continuously, antimicrobial resistance will get in to human's food chain. The resistance can be transferred
\end{abstract}

through several mechanisms including intrinsic, acquired, and adaptive resistance. ${ }^{4}$ Resistance to antibiotics is the most concerning type of antimicrobial resistance. ${ }^{5}$ Human can be exposed to viable, commensal antibiotic resistant bacteria by contact with livestock or inadequately cooked food or cross-contamination. ${ }^{6}$ When microbes become resistant to medicines, the options for treating the diseases they cause are reduced. Antimicrobial resistance threatens the ability to treat infectious diseases, resulting in prolonged illnesses, increased morbidity and mortality, prolonged length of stay in hospital, loss of protection for patients undergoing operations and other medical procedures, and increased health care cost. Antimicrobial resistance affects all areas of health, involves 
many sector and has an impact on the whole of society.

Escherichia coli is Gram-negative bacteria which is normally living as gut commensal microorganism. It is also included as indicators of food contamination due to fecal material. About $10-15 \%$ strains of $E$. coli can cause food-borne diseases. $^{8}$ E. coli also becomes responsible of nosocomial infection in the hospital. And now, E. coli is also the indicator in antibiotic resistance issues. ${ }^{9}$ Cefotaxime, the third generation of cephalosporins, is formerly known to be effective to eradicate $E$. coli as it is also included as antibiotic for hospital acquired Gram-negative bacteria. However, there is a dramatic increase of cephalosporins-resistant- $E$. coli due to intensive use of antimicrobial agents in animal production.

Staphylococcus aureus is commensal bacteria in human that may become pathogenic in some cases. ${ }^{10}$ It is also responsible of infectious disease in food-producing animal. ${ }^{11}$ Food-producing animal has been identified as one of the source of Methicillin-Resistant $S$. aureus. ${ }^{12}$ The mecA gene in Methicillin-Resistant $S$. aureus codes Penicillin Binding Protein 2a (PBP2a) with low affinity, resulting resistance as the aftermath. Several studies had explained that antimicrobial susceptibility test using cefoxitin with disk diffusion method give good result to detect mecA gene. ${ }^{13}$ In this study, we used cefoxitin to determine Methicillin-Resistant $S$. aureus (MRSA).

This study designed to identify the occurrece of resistance from chicken meat which may enter the human food chain as the consumer. This study used samples from traditional and modern market in Surabaya, East Java, Indonesia. This could provide important information, not only for Surabaya city, but also for other region in Indonesia as well due to local microorganisms spreading.

\section{Methods}

Based on the data collection, this study was classified as observational research with posttest only design because researchers observed sensitivity of bacterial isolates to certain antibiotics. Based on the data analysis, this research was classified as descriptive research because the data was analyzed using descriptive statistics in the form of frequency distribution tables.

This research was approved by the ethic committee of Faculty of Medicine, Airlangga University with ethical clearance number 249/EC/KEPK/FKUA/2017. Classical microbiological methods were applied to isolate and identify Staphylococcus aureus and Escherichia coli isolates based on the microbiology laboratory manual on how to culture bacteria from food samples. ${ }^{14}$ Sensitivity test were done based on CLSI 2015 recommendation. This research was held in Microbiology Laboratory, Faculty of Medicine, Airlangga University, Surabaya during February 2018.

\section{Preparation of Chicken Meat Samples}

Samples of 1 gr chicken meat were blended, added with $9 \mathrm{ml}$ sterile distilled water and mixed for about 5 minutes to be a suspension. The samples were then processed in to serial dilution of $10^{-2}, 10^{-3}$, and $10^{-4}$. Bacteria from $10^{-5}, 10^{-6}$, and $10^{-7}$ diluted suspension were inoculated with spread plate method to three nutrient agar plates. Bacteria from $10^{-1}$ diluted suspension were inoculated with four-way streaking method into eosine methylene blue agar and mannitol salt agar. These processes were done aseptically. All of the media were then incubated at $37^{\circ} \mathrm{C}$ for 24 hours.

\section{Presumptive Identification Test of Bacterial Specimen}

E. coli was presumptively identified when there was green metallic sheen colony with dark black in the center of it on eosine methylene blue agar due to lactose fermentation. $S$. aureus was presumptively identified when there was yellow colony on mannitol salt agar due to mannitol fermentation. Bacterial colonies from each plate of the three nutrient agar plates were counted using Total Plate Count (TPC) formulation.

\section{Confirmative Identification Test of Bacterial Specimen}

Gram staining was done aseptically from the identified colonies. The bacteria were confirmatively identified using electrical microscope with $1000 x$ magnification in total. $E$. coli appeared as Gram-negative coccobacilli bacteria and red colored. S. aureus appeared as Gram-positive coccus bacteria and purple colored. S. aureus also had positive result of catalase test.

\section{Antimicrobial Sensitivity Test}

Media plates were stored in refrigeration at $4^{\circ} \mathrm{C}$ for 24 hours. The next day, antimicrobial sensitivity test was done with Kirby-Bauer disk diffusion method, based on CLSI 2015 guideline. E. coli and $S$. aureus isolates from each sample were then processed to be $10^{-1}$ diluted suspension with normal saline and equilibrated to a $0.5 \mathrm{McF}$ arland Standard turbidity or approximately $1.5 \times 108$ Colony Forming Unit (CFU)/cc or 250-300 colonies in solid medium. E. coli and S. aureus were inoculated on Mueller-Hinton agar using sterile cotton swab. All culture plates were allowed to dry for about 5 minutes. Cefotaxime $30 \mu \mathrm{g}$ were aseptically placed on the surface of every Mueller Hinton agar with E. coli. Cefoxitin 30 $\mu$ g were aseptically placed on the surface of every Mueller Hinton agar with $S$. aureus. The antibiotic discs were gently pressed using sterile forceps. All plate cultures were incubated in an inverted position for 24 hours at $37^{\circ} \mathrm{C}$. The next day, all plate cultures was examined for the presence or absence of a zone of inhibition surrounding each disc. Using caliper, the inhibited zones were measured to the nearest millimeter. The results were then compared with CLSI 2015 and determined for the susceptibility of each sample. ${ }^{15}$

Results

Table 1. Bacterial Contamination of Retail Chicken Meat

\begin{tabular}{lccc}
\hline Location & $\begin{array}{l}\text { Escherichia } \\
\text { coli }(\%)\end{array}$ & $\begin{array}{l}\text { Staphylococcus } \\
\text { aureus }(\%)\end{array}$ & $\begin{array}{l}\text { Total Colony } \\
\text { on Nutrient } \\
\text { Agar }(\%)\end{array}$ \\
\hline $\begin{array}{l}\text { Traditional } \\
\text { Markets }\end{array}$ & $4(100)$ & $4(100)$ & $\begin{array}{c}>10-5 \mathrm{cfu} / \mathrm{ml} \\
(100)\end{array}$ \\
\hline $\begin{array}{l}\text { Modern } \\
\text { Markets }\end{array}$ & $0(0)$ & $4(100)$ & $\begin{array}{c}>10-5 \mathrm{cfu} / \mathrm{ml} \\
(100)\end{array}$ \\
\hline
\end{tabular}

This is the first study identifying $E$. coli and $S$. aureus contamination and resistance of retail chicken meat samples bought from selected traditional and modernmarketsinSurabaya. It was shown that all chicken meat samples from both kinds of markets were highly contaminated with microorganisms. It was more than $105 \mathrm{cfu} / \mathrm{ml}$. It was beyond Indonesian National Standard Safe Margin for Bacterial Contamination of Food. ${ }^{11}$ The high contamination rate of modern markets chicken meat sample is surprising because of the clean appearance provided by the markets, which is considered the most important reason for the consumer to buy there. 
Table 2. The Result of Identification and Antibiotic Resistance Test

\begin{tabular}{cccccc}
\hline \multirow{2}{*}{ Location } & $\begin{array}{c}\text { Sample } \\
\text { Code }\end{array}$ & Escherichiacoli & $\begin{array}{c}\text { Cefotaximeresistance } \\
\text { Escherichiacoli }\end{array}$ & $\begin{array}{c}\text { Staphylococcus } \\
\text { aureus }\end{array}$ & $\begin{array}{c}\text { Cefoxitin resistance } \\
\text { Staphylococcus aureus }\end{array}$ \\
\hline \multirow{4}{*}{ Traditional Markets } & T1 & + & Sensitive & + & Sensitive \\
\cline { 2 - 6 } & T2 & + & Sensitive & + & Sensitive \\
\cline { 2 - 6 } & T3 & + & Sensitive & + & Sensitive \\
\hline \multirow{2}{*}{ Modern Markets } & M1 & + & Sensitive & + & Sensitive \\
\cline { 2 - 6 } & M2 & - & - & + & Sensitive \\
\cline { 2 - 6 } & M3 & - & - & + & Sensitive \\
\hline
\end{tabular}

This study also shown that all chicken meat samples from traditional markets selected in Surabaya were contaminated with E. coli $(\mathrm{n}=4 / 4)$. However, E. coli was not found in chicken meat samples from selected modern markets in Surabaya $(\mathrm{n}=0 / 4)$. All E. coli cultures found in traditional markets chicken meat sample were still sensitive to cefotaxime $(n=4 / 4)$. S. aureus were found in all chicken meat samples from the markets $(n=8 / 8)$. All $S$. aureus obtained from traditional markets chicken meat samples were still sensitive to cefoxitin $(n=4 / 4)$. However, two chicken meat samples from modern markets $(n=2 / 4)$ were resistant to cefoxitin.

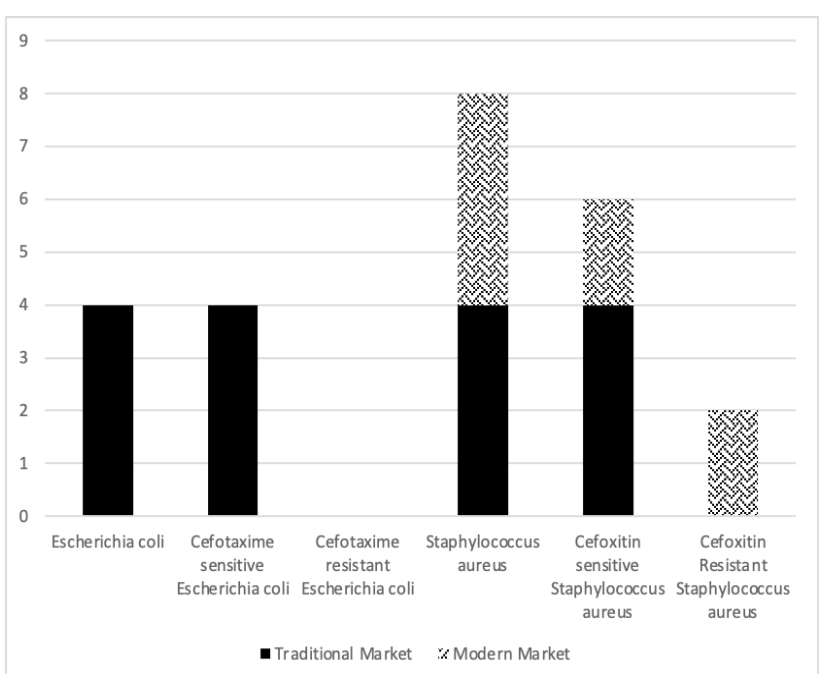

Figure 1. Bacterial Contamination and Antibiotic Resistance in Chicken Meat Samples Column Chart

\section{Discussion}

The Presence of Bacterial Contamination of Chicken Meat Bacterial contamination of chicken meat can be related with some sources such as the surface of the used tools, water, and microorganisms of the chicken.16 Another study explained that bacterial contamination in the food comes from various resources including soil, water, food utensils, enteric microorganisms of humans and animals, food handlers, animal hides and feeds. ${ }^{17}$ In accordance to those researches, in this study, the environment in traditional markets played major role in the occurrence of bacterial contamination. Retail chicken meats from traditional markets were all exposed to external environment, presented without any wrap. A study in United States of America showed that gloves used for pulling-out the chicken feathers were correlated with the increase of bacterial contamination. This would be worsened by the food handlers who did not wash their hands before processing the chicken meat. ${ }^{18}$

\section{E. coli and $S$. aureus in Chicken Meat}

The presence of $E$. coli revealed fecal contamination in the food. ${ }^{19}$ Meanwhile, the absence of $E$. coli was correlated to better hygiene provided by modern markets. The chicken meats were cleanly wrapped. On the contrary, the butchers in traditional markets sold the chicken meat on the side of the road, directly exposed to the air and dust. They also sold the chicken meat without formerly removing the anal part. Study in Taif, Saudi Arab, found that E. coli in raw chicken meat samples contained resistance gene correlated with urinary tract infection in human due to poultry consumption. ${ }^{20}$ This is one of the reasons why society should pay more attention for bacterial contamination in the food.

\section{The Presence of Resistance in Chicken Meat}

This study revealed that there was resistance of $S$. aureus towards cefoxitin. Cefoxitin was known to be used as better antibiotic than oxacillin to judge MethicillinResistant S. aureus (MRSA).21 Among four chicken meat samples bought from modern markets in Surabaya, two of them were resistant towards cefoxitin. A study performed in Denmark also showed high amount of MRSA in contaminated meat. ${ }^{22}$ While, studies in Malaysia had found MRSA in pigs and the food handlers ${ }^{23}$ Slaughterhouse personnel were reported to have a high MRSA carriage rage in poultry. ${ }^{24}$

The presence of MRSA in food-producing animal product for human consumption is now a public health problem. The resistance in $S$. aureus could be transferred through some mechanisms including conjugation, bacteriophage transduction, and transformation. ${ }^{25}$ This study demonstrated that out of 8 chicken samples tested, 2 samples were confirmed positive for cefoxitin resistant $S$. aureus. This result corresponds with the findings by Ugwu et al. (2015) in Nigeria and Mkize at al. (2017) in South Africa.26,27 They cultured $S$. aureus from chicken meat samples in the market and performed antibiotic sensitivity tests. The antibiotic they tested includes tetracycline, ampicillin, chloramphenicol, gentamicin, kanamycicn, streptomycin, vancomycin, cefoxitin, trimethoprim and erythromycin. In previous comparative studies, tetracycline 
resistance was the most prevalent compared to other antimicrobial agents. Tetracycline is known to be widely used in poultry due to its cheap cost and fewer side effects to promote growth.

Studies in European countries documented MRSA ST398 infections in humans. ${ }^{28}$ Some studies suggested that MRSA in animal could be transmitted human. It was also studied in a case control design that human with MRSA CC398 had eaten significantly more amount of chicken meat than the control group. ${ }^{29}$ This was indicating that contaminated meat could be the source of MRSA transmitted to human. Besides, MRSA could be transmitted from animal to human through some methods such as direct contact, environmental contamination and handling contaminated meat. ${ }^{30}$ This study showed us that MRSA had entered human food chain in Surabaya, Indonesia and it is now a treat to human since the resistance gene from the bacteria could be transferred. In the future, we need to limit antimicrobial use in food animals in order to reduce antimicrobial resistance in food animals, thereby antimicrobial resistance in human population can be hopefully reduced. Several measures has been proposed by WHO to tackle this problem including raising global awareness about the associated risks and danges of nontherapeutic antibiotic usage, synchronizing national surveillance systems with regional and global systems, collecting as much data as possible about the antimicrobial agents in human and animals, maintaining hygienic condition to reduce the risk of infection, safely handling healthy food products, and implementing regulations for effective licensures of antibiotics, their distribution and dispensing. ${ }^{7}$

\section{Conclusion}

Chicken meat from both traditional and modern markets in Surabaya have been highly contaminated with bacteria. Even more, antibiotic resistance is found. It is an alarm for all of us to keep eye wide open because antibiotic resistances have already entered human food chain. Since the resistance gene could possibly be transferred in to human population, food-processing should be conducted correctly. People should pay attention to proper handling of raw meat, adequate cleaning of hands, surfaces, equipment, disinfection of poultry slaughter houses, vehicles and good personal hygiene to reduce the spreading of MRSA. There should be a strict global policy regarding non-therapeutic antibiotic issue. The researcher suggests that further studies and investigations on the poultry are needed.

\section{Conflict of Interest}

The author stated there is no conflict of interest

\section{References}

1. Ventola L. The Antibiotic Resistance Crisis. Pharm Ther. 2015;40(4):277-83.

2. Garedew L, Hagos Z, Zegeye B, Addis Z. The detection and antimicrobial susceptibility profile of Shigella isolates from meat and swab samples at butchers' shops in Gondar town, Northwest Ethiopia. J Infect Public Health. 2016;9(3):348-55

3. Skočková A, Koláčková I, Bogdanovičová K, Karpíšková R. Characteristic and antimicrobial resistance in Escherichia coli from retail meats purchased in the Czech Republic. Food Control. 2015;47:401-6.

4. Hughes D, Andersson DI. Environmental and genetic modulation of the phenotypic expression of antibiotic resistance. FEMS Microbiol Rev. 2017;41(3):374-91

5. Andleeb S, Majid M, Sardar S. Environmental and public health effects of antibiotics and AMR/ARGs. Antibiotics and Antimicrobial Resistance Genes in the Environment. Elsevier Inc.; 2020. 269-291 p.

6. Thakare R, Kesharwani P, Dasgupta A, Srinivas N. Antibiotics : Past, Present, and Future [Internet]. Drug Discovery Targeting DrugResistant Bacteria. Elsevier Inc.; 2020. 1-8 p.

7. WHO. Global Antimicrobial Resistance Surveillance System (GLASS) Report. Who. 2017.

8. Lambrecht E, Van Coillie E, Van Meervenne E, Boon N, Heyndrickx M, Van de Wiele T. Commensal E. coli rapidly transfer antibiotic resistance genes to human intestinal microbiota in the Mucosal Simulator of the Human Intestinal Microbial Ecosystem (M-SHIME). Int J Food Microbiol. 2019;311(August):108357.

9. Capita R, Riesco-Peláez F, Alonso-Hernando A, Alonso-Calleja C. Exposure of Escherichia coli ATCC 12806 to sublethal concentrations of food-grade biocides influences its ability to form biofilm, resistance to antimicrobials, and ultrastructure. Appl Environ Microbiol. 2014;80(4):1268-80.

10. Tong SYC, Davis JS, Eichenberger E, Holland TL, Fowler VG. Staphylococcus aureus infections: Epidemiology, pathophysiology, clinical manifestations, and management. Clin Microbiol Rev. 2015;28(3):603-61.

11. Feltrin F, Alba P, Kraushaar B, Ianzano A, Argudín A, Matteo D. A Livestock-Associated, Multidrug-Resistant, Methicillin-Resistant Staphylococcus aureus Clonal Complex 97 Lineage Spreading in Dairy Cattle and Pigs in Italy. 2016;82(3):816-21.

12. Velasco V, Buyukcangaz E, Sherwood JS, Stepan RM, Koslofsky RJ, Logue CM. Characterization of staphylococcus aureus from humans and a comparison with isolates of animal origin, in North Dakota, United States. PLoS One. 2015;10(10):1-15.

13. Swenson JM, Tenover FC, Addison R, D'Souza H, O'Connor J, Rothberg J, et al. Results of disk diffusion testing with cefoxitin correlate with presence of mecA in Staphylococcus spp. J Clin Microbiol. 2005;43(8):3818-23.

14. Cappuccino JG, Welsh C. Microbiology; A Laboratory Manual. Eleventh. Microbiology. Harlow, Essex, England: Pearson; 2017.

15. CLSI. Performance Standards for Antimicrobial Susceptibility Testing; Twenty-Fifth Informational Supplement. Wayne, PA: Clinical and Laboratory Standards Institute; 2015.

16. BSN. Standar Nasional Indonesia 7388:2009 Tentang Batas Maksimum Cemaran Mikroba Dalam Pangan. 2009.

17. Rouger A, Tresse O, Zagorec M. Genetic and nutrition development of indigenous chicken in Africa. Microorganisms. 2017;5(50).

18. Nyamusore J, Nahimana MR, Ngoc CT, Olu O, Isiaka A, Ndahindwa $\mathrm{V}$, et al. Risk factors for transmission of Salmonella Typhi in Mahama refugee camp, Rwanda: A matched case-control study. Pan Afr Med J. 2018;29:1-13.

19. Adeyanju GT, Ishola O. Salmonella and escherichia coli contamination of poultry meat from a processing plant and retail markets in Ibadan, Oyo state, Nigeria. Springerplus. 2014;3(1):1-9.

20. Altalhi AD, Gherbawy YA, Hassan SA. Antibiotic Resistance in Escherichia coli Isolated from Retail Raw Chicken Meat in Taif, Saudi Arabia. Foodborne Pathog Dis. 2010;7(3):281-5.

21. Yamamoto T, Nishiyama A, Takano T, Yabe S, Higuchi W, Razvina $\mathrm{O}$, et al. Community-acquired methicillin-resistant Staphylococcus aureus: Community transmission, pathogenesis, and drug resistance. J Infect Chemother [Internet]. 2010;16(4):225-54.

22. Tang Y, Larsen J, Kjeldgaard J, Andersen PS, Skov R, Ingmer H. Methicillin-resistant and -susceptible Staphylococcus aureus from retail meat in Denmark. Int J Food Microbiol [Internet]. 2017;249:726.

23. Neela V, Zafrul AM, Mariana NS, Van Belkum A, Liew YK, Rad EG. Prevalence of ST9 methicillin-resistant Staphylococcus aureus among pigs and pig handlers in Malaysia. J Clin Microbiol. 2009;47(12):4138-40.

24. Mulders MN, Haenen APJ, Geenen PL, Vesseur PC, Poldervaart ES, Bosch T, et al. Prevalence of livestock-associated MRSA in broiler flocks and risk factors for slaughterhouse personnel in the Netherlands. Epidemiol Infect. 2010;138(5):743-55.

25. Haaber J, Penadés JR, Ingmer H. Transfer of Antibiotic Resistance in Staphylococcus aureus. Trends Microbiol [Internet]. 
2017;25(11):893-905.

26. Ugwu IC, Anyanwu MU, Ugwu CC, Okoro JC. Isolation and Detection of Methicillin-Resistant Staphylococci in Healthy Broilers in Nsukka Southeast, Nigeria. Not Sci Biol. 2015;7(1):20-5.

27. Mkize N, Zishiri OT, Mukaratirwa S. Genetic characterisation of antimicrobial resistance and virulence genes in Staphylococcus aureus isolated from commercial broiler chickens in the Durban metropolitan area, South Africa. J S Afr Vet Assoc. 2017;88(1):1-7.

28. Witte W, Strommenger B, Stanek C, Cuny C. Methicillin-resistant Staphylococcus aureus ST398 in Humans and Animals, Central Europe. Emerg Infect Dis. 2007;13(2):255-8.
29. van Rijen MML, Kluytmans-van den Bergh MFQ, Verkade EJM, ten Ham PBG, Feingold BJ, Kluytmans JAJW, et al. Lifestyle-Associated Risk Factors for Community-Acquired Methicillin-Resistant Staphylococcus aureus Carriage in the Netherlands: An Exploratory Hospital-Based Case-Control Study. PLoS One. 2013;8(6):1-7.

30. Verkade E, Kluytmans J. Livestock-associated Staphylococcus aureus CC398: Animal reservoirs and human infections. Infect Genet Evol. 2014;21:523-30. 